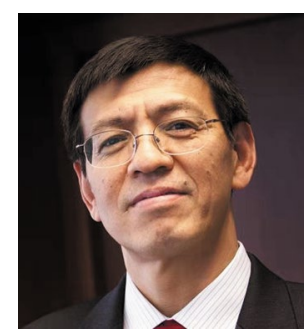

\title{
Economics in food systems transformation
}

\author{
Economists must embrace the food systems approach and emerging economies must engage \\ in setting the global food systems agenda, argues Shenggen Fan.
}

Credit: Shenggen Fan

$\mathrm{O}$ ver several years, there have been numerous reports on food systems transformation highlighting key transitions, strategies and actions needed to shift towards healthy diets, promote sustainable production practices, protect and restore nature and reduce food waste and $\operatorname{loss}^{1-3}$. And yet, there is generally a lack of in-depth economic analysis of the proposed strategies and actions. This is a lost opportunity for economists as well as for food systems transformation. Furthermore, despite rapid ascension in global food production, consumption, trade and investment, the voices of emerging economies including China, India and Brazil are largely absent in setting the global food systems agenda. This will hinder the transformation of their own as well as the global food systems.

In January 2020, after 35 years of overseas study and research on food policy (including 25 years with the International Food Policy Research Institute) I came back to China. With colleagues, I established the Academy of Global Food Economics and Policy (AGFEP) at China Agricultural University with an aim to provide research and advice to Chinese and global decision makers to shape food systems to deliver better health and environmental outcomes. In my view, economics can make a unique contribution to food systems transformation, and emerging economies must be more engaged in setting the global food systems agenda.

\section{Contribution of economics}

Food systems are both a victim of and a contributor to environmental degradation and climate change, and a cause of many health crises including the triple burden of malnutrition (hunger, micronutrient deficiencies and overweight/obesity), food safety scares and zoonotic pandemics such as the ongoing COVID-19 pandemic.

The definition and scope of food systems have evolved over time. They differ from food value chains, which consist of all the stakeholders in the production of food and value-adding activities. But food systems are far broader and are defined as the sum of actors, sectors and interactions along the food value chains $-\mathrm{R} \& \mathrm{D}$, input supply, production, harvesting, storage, transportation, processing, retailing, wholesaling, preparation, consumption and disposal of food. Massive externalities on environment, climate change and health are part of food systems. Food systems also include the enabling policy environment and cultural norms around food.

Economics, at its essence, is the analysis of private and public choice under scarcity, including the policies needed to incentivize socially optimal behaviours around healthy consumption and sustainable production of food. Economists can make five key contributions to the analysis of food systems.

Food systems have massive externalities and contribute to the violation of most planetary boundaries. Economists can develop methods and metrics to account for the true cost of food systems. The costs need to be internalized through taxation and regulations, so food prices reflect true costs to the environment, climate change and health. The Food and Land Use Coalition estimated that environmental, health and social costs amounted to at least US\$12 trillion a year - larger than the value of the food system's global output measured at market prices ${ }^{1}$.

Economists can identify synergies among efficiency, sustainability, health and social inclusion goals. Many strategies and actions to improve efficiency, for example, may also improve health and inclusiveness. They include trade regimes to stabilize prices and lower food costs for consumers, measures to reduce food loss and waste, innovative technologies that can both increase efficiency and promote more diversified production and diets, and infrastructure investments that could potentially benefit multiple food system goals. Similarly, economists can help design polices and strategies to minimize trade-offs among different goals.
Economists can help analyse the solution to policy failures. For example, the subsidies in food and agriculture distort both domestic and global food markets, lead to over-use of water, land and chemical inputs, increase GHG emissions, and distort resource allocation among foods to the detriment of diverse diets and health. Public funds could be redirected towards the production and consumption of healthy and sustainable foods such as fruits, vegetables, beans and nuts, through R\&D investment and value chain development.

Economists can improve understanding of political decision-making processes. It is important to understand the incentives of interest groups within entire food systems, including those emerging from technological advances (for example, genetically modified or edited crops and biotechnology, and regenerative agriculture), multinational corporations, the food retail sector and environmental groups.

Finally, economists can provide a diverse and rigorous toolkit for understanding choice under scarcity and the trade-offs between different system objectives, including microeconomic analyses of consumer and producer behaviours, meso-level analyses of markets and value chains, and macro-level modelling of entire economies and the global food system as a whole. But economists should not work alone or in silos. It is more important than ever to work together across disciplines such as natural resources, environment, climate, nutrition and health.

\section{China and the global food systems agenda}

Taking China as an example, the country's food systems are facing the same challenges as in other countries that threaten both human and planetary health. Fortunately, the government has recently made several important commitments on health, the environment and climate change including achieving carbon neutrality by 2060 . This gives a unique opportunity to reshape food systems to achieve these national goals. 
Chinese food systems have global implications as the country is the largest producer, importer and exporter of many food commodities, biggest greenhouse gas emitter, and has become the leading R\&D investor in food and agricultural systems for both public and private sectors. It is a key player in global development issues and actively participates in 'South-South cooperation'. The country has launched the One Belt and One Road Initiative to strengthen investment cooperation with Asia, Africa and Latin America. The question is how these initiatives can help achieve win-win outcomes, particularly in food systems transformation, for both China and recipient countries.
In this context, AGFEP will try to break traditional disciplinary boundaries to study food, nutrition, health, environmental resources, climate mitigation and adaptation holistically by using the food systems approach. The mission is to provide high-quality data and research, as well as evidence-based policy advocacy and capacity strengthening at all levels. It is my sincere hope that AGFEP will serve as a two-way bridge between international food systems research and the national food systems transformation in China.

Shenggen Fan ${ }^{1,2}$ 四

${ }^{1}$ Chair Professor, College of Economics and
Management, China Agricultural University, Beijing, China. ${ }^{2}$ Dean, Academy of Global Food Economics and Policy, China Agricultural University, Beijing, China.

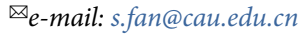

Published online: 21 April 2021

https://doi.org/10.1038/s43016-021-00266-0

References

1. Growing Better: Ten Critical Transitions to Transform Food and Land Use (Food and Land Use Coalition, 2019).

2. Future Food Systems: For People, Our Planet, and Prosperity (Global Panel on Agriculture and Food Systems for Nutrition, 2020).

3. Willett, W. et al. Lancet 393, 447-492 (2019).

Competing interests

The author declares no competing interests. 